Revista Iberoamericana. Vol. LXVII, Núms. 194-195, Enero-Junio 2001, 267-280

\title{
OCTAVIO PAZ: EL MITO Y LA HISTORIA EN EL LABERINTO DE LA SOLEDAD
}

\author{
POR \\ HÉCTOR JAIMES \\ North Carolina State University
}

\begin{abstract}
El laberinto de la soledad (1950) es quizá el libro de ensayos de mayor importancia que haya escrito el poeta y ensayista mexicano Octavio Paz (1914-1998). Aunque contiene muchos de los temas anteriormente tratados por sus predecesores, ${ }^{1}$ se puede decir que uno de sus pilares fundamentales lo constituye el tema en torno a la filosofía de lo mexicano. Para Abelardo Villegas, la inspiración de este libro es sin duda El perfil del hombre y la cultura en México (211) del filósofo mexicano Samuel Ramos. Sin embargo, ver esta fuente como el progenitor directo de la obra de Paz resulta claramente problemático, sobre todo si tomamos en cuenta la variedad de autores y títulos que se discuten en ella: Jacques Soustelle, La pensée cosmologique des anciens mexicains (1940); Ricardo Pozas, Juan Pérez Jolote, Autobiografía de un tzotzil (1959); Edmundo O’Gorman, Crisis y porvenir de la ciencia histórica (1947); Leopoldo Zea, El positivismo en México (1942); Jesús Silva Herzog, Meditaciones sobre México (1946); Gabino Fraga, El derecho agrario (1946); Lucien Lévy-Bruhl, La mentalité primitive (1922); y Amable Audin, Les Fêtes Solaires (1945), entre otros. Entonces, ¿cómo hallar la fuente de inspiración del ensayista mexicano al escribir su obra? Si bien es cierto que El perfil del hombre y la cultura en México es el primer intento de elaborar una filosofía de lo mexicano, así como de su carácter y personalidad, igualmente cierto es que Paz — aunque lee a Ramos— no se propone una simple superación; es decir, no lo comenta para superarlo (o para destruirlo), sino para asimilarlo. ${ }^{2}$ De la misma
\end{abstract}

\footnotetext{
${ }^{1}$ En este sentido, Stephen J. Homick afirma que: "La fuerza motriz de la emancipación mental mexicana fue el insigne Ateneo de la Juventud. Entre sus socios contaban a Antonio Caso, José Vasconcelos y el dominicano Pedro Henríquz Ureña. En gran parte, su obra fue los fundamentos de una filosofía bien arraigada en la realidad de México; y como veremos, el pensamiento de esos jefes de la revolución espiritual en México influiría en las ideas de sus sucesores, inclusive las de Octavio Paz" (101-02).

${ }^{2} \mathrm{Al}$ hablar de El laberinto de la soledad en su libro Posdata (1970) (texto que sirve de continuación a El laberinto de la soledad) el ensayista dice: "En El laberinto de la soledad me esforcé por eludir (claro, sin lograrlo del todo) tanto las trampas del humanismo abstracto como las ilusiones de una filosofía de lo mexicano: la máscara convertida en rostro / el rostro petrificado en máscara. En aquella época no me interesaba la definición de lo mexicano, sino, como ahora, la crítica: esa actividad que consiste, tanto más que en conocernos, en liberarnos” (11-12); y en El ogro filantrópico (1979), apunta: "yo no quise hacer ni ontología ni filosofía del mexicano. Mi libro es un libro de crítica social, política y psicológica. Es un libro dentro de la tendencia francesa del ‘moralismo’. Es una descripción
} 
manera, la obra de Paz no ha sido el único libro que revise la mexicanidad desde la publicación de El perfil; las obras de O’Gorman y de Zea, así como la del filósofo español José Gaos, han sido también aportes importantes sobre el tema. Es cierto: El laberinto tiene un punto de partida, pero no es fijo e inmediato; es más bien impreciso, heterogéneo, y en eso consiste su complejidad y su belleza. Asimismo, uno de los puntos más resaltantes de la obra y al que la crítica le ha dado poca atención, es la relación entre el mito y la Historia; relación — por lo demás - que presenta una revolucionaria propuesta historiográfica: entender e interpretar la Historia a partir del mito. Será entonces la relación entre estos dos ejes y sus repercusiones en la historiografía y en el género ensayístico, lo que analizaré en este artículo.

Toda interpretación de la Historia lleva implícita la noción de su reescritura. Es en la escritura donde el pasado cobra fuerza y sentido; sin ésta, la Historia tan sólo se comprendería como el movimiento humano en el tiempo, mas no como su registro. En este sentido, es frecuente observar que la Historia de un país ha sido escrita de diversas maneras o bajo ángulos distintos; el hecho histórico, entonces, que es uno de los puntos de partida del historiador, es susceptible a múltiples interpretaciones. Por lo tanto, lo que conformaría la versión “oficial” de dicho hecho, muy bien puede ser un conglomerado historiográfico que coincida, refute o complemente las versiones anteriores. Por Historia podemos entender la agrupación de una serie de interpretaciones sobre un evento o serie de eventos ocurridos en el pasado. Todas estas interpretaciones dan por sentado y a modo de premisa, que los hechos referidos son verídicos y dignos de registro. Vemos así que el hecho histórico sirve de piso ontológico a la escritura de la Historia: sin autenticidad de lo ocurrido no hay discurso. Bajo esta perspectiva, no se cuestiona al hecho histórico o al documento, ya que éstos son el medio más fidedigno para dar validez a la escritura. Existe entonces una relación casi simétrica entre lo ocurrido y lo narrado; no hay conjeturas amplias o ambiguas, tan sólo un recuento de la realidad sucedida. Así, esta metodología historiográfica pretende ser más científica y rigurosa que las que se apoyan en hechos supuestos; pero, ¿ipierden en realidad veracidad y rigurosidad las Historias basadas no sólo en lo ocurrido, sino en representaciones míticopoéticas de la realidad de un pueblo? El laberinto de la soledad, que aspira a ser ensayo en la medida en que es reescritura de la Historia, es el mejor intento de respuesta a estas preguntas, ya que Paz se basa en el mito para socavar las pretenciones cientificistas de la historiografía tradicional.

El libro está constituido por ocho ensayos (I. "El pachuco y otros extremos", II. “Máscaras mexicanas”, III. “Todos santos, día de muertos”, IV “Los hijos de la Malinche”,

de ciertas actitudes, por una parte y, por la otra, un ensayo de interpretación histórica” (20). Asimismo, en Crítica de la razón latinoamericana, Santiago Castro-Gómez señala, al criticar la filosofía de Leopoldo Zea, el problema de las fisuras discursivas, y su relación con lo que Foucault ha llamado "genealogía”: "Detrás de los discursos latinoamericanistas ya no se ubica un 'sujeto', entendido como origen de los mismos, sino un conjunto de relaciones de fuerzas, intereses de clase y luchas de poder que 'generan' tanto a los sujetos como a los discursos ... en lugar de crear narrativamente una serie de continuidades que harían posible reconstruir la evolución del pensamiento latinoamericano, tal como nos propone Zea, la genealogía se ocupa de mostrar las rupturas, los vacíos, las fisuras y las líneas de fuga presentes en la historia” (116-17). 
V. “Conquista y Colonia”, VI. “De la independencia a la Revolución”, VII. “La ‘inteligencia” mexicana”, VIII. “Nuestros días”) y en la segunda edición (1959) aparece un apéndice (“La dialéctica de la soledad"). Todas estas secciones se hallan relacionadas de distintas maneras con la visión que tiene el ensayista sobre la Historia; de la misma manera, podemos reconocer la historicidad de las acciones de los individuos. Sin embargo, detrás de estas acciones existen elementos más profundos y complejos que también las determinan; a saber: los mitos. Así leemos:

\begin{abstract}
El tiempo mítico, al contrario [del tiempo histórico], no es una sucesión homogénea de cantidades iguales, sino que se halla impregnado de todas las particularidades de nuestra vida: es largo como una eternidad o breve como un soplo, nefasto o propicio, fecundo o estéril.

Esta noción admite la existencia de una pluralidad de tiempos. Tiempo y vida se funden y forman un solo bloque, una unidad imposible de escindir. (El laberinto 358)
\end{abstract}

Y más adelante dice: "el Mito — disfrazado, oculto, escondido- reaparece en casi todos los actos de nuestra vida e interviene decisivamente en nuestra Historia: nos abre las puertas de la comunión” (360). En este sentido, Rocío Oviedo afirma que “la temporalidad, en El laberinto ... es un tiempo centrado en la realidad histórica — para refutar las teorías de Samuel Ramos y partiendo de conceptos histórico-culturales como los de José Gaos, Ortega y Spengler-. Pero a su vez es un tiempo impreciso. La imprecisión viene otorgada no por la creación de un tiempo mítico, sino porque el presente, carente de bases, contagia de irrealidad al pasado conocido"(24). ${ }^{3}$

Para la interpretación del pasado, esta fusión de lo histórico y lo mítico podría concebirse como una conjunción de términos incompatibles. La Historia se ha concebido como el relato de hechos verdaderos, mientras que el mito como el relato de hechos falsos o inventados. En Myth and Reality, Mircea Eliade estudia aquellas sociedades que concebían el mito como un hecho real, y en este sentido, como elemento presente dentro de la cultura. Su definición del mito es totalizante, y hace posible la integración de la Historia y el mito, de manera similar a la de Paz: "Myth narrates a sacred history; it relates an event that took place in primordial Time, the fabled time of the 'beginnings' ... Myth tells only of that which really happened, which manifested itself completely” (6). Basándonos en la definición de Eliade, podemos observar que la realidad no niega al mito, sino más bien lo ratifica y le da valor. Según esta interpretación el mito no existe fuera de la realidad; él es prácticamente lo real porque se manifiesta en lo tangible. La concepción mítica del poeta mexicano muy bien se puede emparentar con la postura anteriormente expuesta, ya que ve al mito como dador de verdad. Así, en El laberinto de la soledad la Historia y el mito no se excluyen ni se contradicen, sino que entran en un profundo juego hermenéutico para descifrar el pasado del pueblo mexicano. De esta manera, el libro es más mitológico que psicológico, pero más mito-histórico que mitológico a secas. Al mismo tiempo, a la comprensión del pasado que propone Paz le acompaña una serie de explicaciones históricas

\footnotetext{
${ }^{3}$ Véase también el artículo de Thomas Mermall, “Octavio Paz: El laberinto de la soledad y el sicoanálisis de la historia”.
} 
cargadas con un tono poético sorprendente; en este sentido, el mito no socava la poesía sino que la evoca. En esta línea de idea, si en “todos lados el hombre está solo” (El laberinto 155), esta soledad tiene significados míticos específicos:

la soledad del mexicano, bajo la gran noche de piedra de la Altiplanicie, poblada todavía de dioses insaciables, es diversa a la del norteamericano, extraviado en un mundo abstracto de máquinas, conciudadanos y preceptos morales. En el Valle de México el hombre se siente suspendido entre el cielo y la tierra y oscila entre poderes y fuerzas contrarias, ojos petrificados, bocas que devoran. La realidad, esto es, el mundo que nos rodea, existe por sí misma, tiene vida propia y no ha sido inventada, como en los Estados Unidos, por el hombre. El mexicano se siente arrancado del seno de esa realidad, a un tiempo creadora y destructora, Madre y Tumba. Ha olvidado el hombre, la palabra que lo liga a todas esas fuerzas en que se manifiesta la vida. Por eso grita o calla, apuñalea o reza, se echa a dormir cien años.

La historia de México es la del hombre que busca su filiación, su origen. Sucesivamente afrancesado, hispanista, indigenista, 'pocho', cruza la historia como un cometa de jade, que de vez en cuando relampaguea. En su excéntrica carrera ¿qué persigue? Va tras su catástrofe: quiere volver a ser sol, volver al centro de la vida de donde un día — ¿en la Conquista o en la Independencia? — fue desprendido. Nuestra soledad tiene las mismas raíces que el sentimiento religioso. Es una orfandad, una oscura conciencia de que hemos sido arrancados del Todo y una ardiente búsqueda: una fuga y un regreso, tentativa por restablecer los lazos que nos unían a la creación. (El laberinto 155)

El crítico Enrico Mario Santí califica al libro como un “complejo cruce entre el ensayo moral, la filosofía de la historia, la antropología de la cultura, la psicohistoria y la autobiografía” (“Introducción” 14). Este “complejo cruce” es deducible a partir del primer párrafo. Si para el crítico "todo el primer párrafo hace eco de las ideas de Edouard Spranger (1882-1963), fenomenólogo y educador alemán” (143), una lectura meticulosa del mismo mostrará también la diversidad de matices discursivos que contiene:

A todos, en algún momento, se nos ha revelado nuestra existencia como algo particular, intransferible y precioso. Casi siempre esta revelación se sitúa en la adolescencia. El descubrimiento de nosotros mismos se manifiesta como un sabernos solos; entre el mundo y nosotros se abre una impalpable, transparente muralla: la de nuestra conciencia. Es cierto que apenas nacemos nos sentimos solos; pero niños y adultos pueden trascender su soledad y olvidarse de sí mismos a través de juego o trabajo. En cambio, el adolescente, vacilante entre la infancia y la juventud, queda suspenso un instante ante la infinita riqueza del mundo. El adolescente se asombra de ser. Y al pasmo sucede la reflexión: inclinado sobre el río de su conciencia se pregunta si ese rostro que aflora lentamente del fondo, deformado por el agua, es el suyo. La singularidad de ser — pura sensación en el niño— se transforma en problema y pregunta, en conciencia interrogante. (El laberinto 143)

Aquí saltan a la luz cinco posturas filosóficas que Paz tomará muy en cuenta a lo largo de El laberinto: la lógica, el existencialismo, el psicoanálisis, el marxismo y la dialéctica hegeliana. La primera postura guarda una estrecha relación con la lógica silogística: “Todos” somos hombres; soy hombre, por ende, soy mortal (ser solitarios). Para Santí el fenómeno de la soledad se presenta como algo particular, pero también como algo universal. 
“El ‘a todos’ de la primera oración del libro”, dice el crítico, “es un ‘yo,’ pero también es un 'nosotros' y un 'ellos"” ("Introducción” 83). Este saberse solos en "algún momento” es lo que suscita una visión existencialista de la vida: el situarse en un tiempo y en un espacio; coordenadas que fijan al ser, pero que también le causan angustia (de vida y muerte). Por otro lado, el eco del psicoanálisis se percibe sobre todo en relación al trauma de nacimiento, cuando dice que "apenas nacemos nos sentimos solos”. Asimismo, la categoría de "trabajo”, pilar del marxismo, está igualmente presente al afirmar que "niños y adultos pueden trascender su soledad y olvidarse de sí mismos a través de juego o trabajo [énfasis añadido]” (143). Por último, en cuanto a la dialéctica hegeliana, las últimas tres líneas muestran una clara presencia de la lectura de la Fenomenología del espíritu de Hegel; especialmente, de la primera parte de la primera sección: "Conciencia”. El paralelismo con el filósofo es inocultable; Paz, usando casi la misma fraseología de Hegel afirma que "la singularidad de ser — pura sensación en el niño— se transforma en problema y pregunta, en conciencia interrogante [énfasis añadido]”. En la Fenomenología leemos: “La conciencia, por su parte, es en esta certeza solamente como puro yo, y yo soy en ella solamente como puro éste y el objeto, asimismo, como puro esto" (Fenomenología 63, énfasis añadido). ${ }^{4}$

Esta heterogeneidad discursiva es una clara manifestación de la amplia metodología crítica del ensayista, la cual estará igualmente presente en su manera de interpretar la Historia. Esto es, en El laberinto de la soledad Paz analiza con gran agudeza los eventos más importantes de la Historia de México, pero no se conforma con la simple reproducción de los hechos de manera lineal, ni siquiera con la aceptación, a ciegas, de la validez historiográfica de cada uno de ellos. Por el contrario, en el libro vemos un verdadero ejercicio crítico, ya que en él se cuestiona la fundamentación ontológica de la Historia, así como la posibilidad de que exista una secuencia predecible de los hechos. Además, para el ensayista mexicano no sólo son los eventos los que constituyen la Historia, sino también las creencias de los pueblos, sus religiones; en fin, sus mitos. El laberinto puede también interpretarse como el primer gran intento en la literatura hispanoamericana de ir más allá de lo visible; es decir, de ir más allá de los hechos, para llegar a lo invisible (la interioridad humana). Por otro lado, considérese también que la palabra "laberinto" no sólo significa un edificio compuesto de un gran número de cámaras o habitaciones construidas de tal manera que resulte difícil encontrar la salida; según el Pequeño Larousse Ilustrado, el “laberinto” también es una “composición poética que puede leerse al derecho, al revés o de otras maneras” (609). Igualmente, la palabra “laberinto” alude a la mitología: fue el palacio construido en Creta por Dédalo para el Minotauro. Paz sabe entonces muy bien que el discurso que ha elaborado en su obra es innovador y hermenéuticamente atrevido en relación a las tradicionales posturas historiográficas.

Existe también un sentido metafórico a partir del título mismo del libro. "Laberinto" y "soledad” no son términos que se excluyan; aquí están entrelazados, y pertenecen a una misma entidad. Si el "laberinto" es el cuerpo (lo tangible, lo material), la "soledad" es el alma; si el "laberinto" es la exterioridad, la "soledad" es la interioridad; si el "laberinto" representa la búsqueda, la “soledad” representa el hallazgo; si el “laberinto” es la fuerza, la

\footnotetext{
${ }^{4}$ Enrico Mario Santí observa otra influencia importante del filósofo alemán, sobre todo la que se transparenta en El laberinto en relación a lo que el crítico llama "monismo histórico" (76).
} 
“soledad” es la debilidad. Pero esta debilidad y esta fuerza, este cuerpo y esta alma, no son formas abstractas para designar elementos desconocidos. El "laberinto" y la "soledad" tienen particularmente una significación humana, y es en esto donde reside su importancia, ya que alma, interioridad, búsqueda y debilidad, son manifestaciones de una vida real, existente. De la misma manera, el libro tiene un significado lúdico: el "laberinto" es un juego en donde hay que hallar la única salida cuando en apariencia, existen múltiples. Quien halle la salida gana, por así decirlo. Pero para salir hay que entrar, y he ahí la dificultad. Paz ha construido aquí toda una metáfora del recorrido del hombre por la vida; el "laberinto” pierde importancia si no se recorre, y no puede ser recorrido por la mente, sino por una persona. El individuo, entonces, es quien hace el tránsito, quien busca y quien fracasa, pero de manera más resaltante, es necesario notar que lo que esencialmente constituye a ese cuerpo no es la abstracción hipotética del recorrido, sino la sociedad y los valores que lo determinan; es decir, su Historia.

Paz no ve la Historia de México como el acontecer humano a través de saltos dialécticos, o bajo una función determinista y predecible de los hechos. Desde su punto de vista, a lo largo de su Historia el mexicano ha intentado reconciliarse con un origen mítico que, antes de estar ausente, determina y aparece en su realidad. Esta reconciliación puede verse como la búsqueda del padre o de la madre que realiza el hijo huérfano. En su pasado, el mexicano encontraría no solamente la raíz de su presente, sino su ser primigenio. No se trata entonces de negar la Conquista o la Independencia, sino de ir más allá de estos dos momentos históricos para conocer el pasado mítico. Sólo conociéndolo, se resolverá el problema de la soledad del mexicano. Así dice:

Nuestro grito es una expresión de la voluntad mexicana de vivir cerrados al exterior, sí, pero sobre todo, cerrados frente al pasado. En ese grito condenamos nuestro origen y renegamos de nuestro hibridismo. La extraña permanencia de Cortés y de la Malinche en la imaginación y en la sensibilidad de los mexicanos actuales revela que son algo más que figuras históricas: son símbolos de un conflicto secreto, que aun no hemos resuelto ... El mexicano no quiere ser ni indio, ni español. Tampoco quiere descender de ellos. Los niega. Y no se afirma en tanto que mestizo, sino como abstracción: es un hombre. Se vuelve hijo de la nada. Él empieza en sí mismo.

Esta actitud no se manifiesta nada más en nuestra vida diaria, sino en el curso de nuestra historia, que en ciertos momentos ha sido encarnizada voluntad de desarraigo. Es pasmoso que un país con un pasado tan vivo, profundamente tradicional, atado a sus raíces, rico en antigüedad legendaria si pobre en historia moderna, sólo se conciba como negación de su origen. (El laberinto 225)

En este sentido, para Paz la Historia está llena de mitos, y como no se han comprendido cabalmente, el trabajo historiográfico tradicional será insuficiente para realizar esa tarea. Es decir, la totalidad del acontecer mexicano está lleno de mitos que se entrecruzan con la Historia y la determinan. No hay pues discursos paralelos, sino una mezcla y heterogeneidad de discursos. La Historia no está ni por encima ni por debajo del mito, sino en un diálogo permanente con él.

Una de las críticas más fuertes a la postura del ensayista mexicano, son las que se encuentran en La divina pareja: Historia y mito en Octavio Paz. En este texto, Jorge 
Aguilar Mora ve que las premisas básicas de El laberinto de la soledad como deficientes y vacías. Deficientes, porque nota que el alcance máximo al que puede llegar su perspectiva, es precisamente a una postura poética en relación al mito; así, la concepción del mito de Paz — según Aguilar Mora— desconoce las relaciones concretas de la Historia y lleva todos los postulados a un nivel retórico. Por otro lado, vacías, porque toda la actividad de la Historia queda reducida a un motor abstracto, desconocido, idéntico a sí mismo, que presupone el mito:

Este pasado no tiene para él [Octavio Paz] características concretas, irrepetibles, inasimilables; este pasado nunca es diferente de sí mismo, ni del presente que logra recuperarlo: es Idéntico a sí mismo y sólo espera que la historia se resuelva a su vez en una igualación, en una identidad, para poder reaparecer. O sea, sólo espera que desaparezca la historia. El único enemigo: la diferencia radical, el devenir constante, la materialidad irreductible de la vida histórica. (Aguilar Mora 43)

Y más adelante leemos:

El laberinto tiene como objeto la interpretación de ciertas clases sociales sin nunca llamarlas por su nombre; pero sobre todo, sin aludir nunca a lo que mínimamente se podría tomar como un comportamiento específico de clase, histórico, económico [...] Se apoya en la noción de clase para no citarla, pero al mismo tiempo invierte el objeto: la clase dominante no es el objeto del libro, pero sí su fundamento conceptual. $\mathrm{O}$ al revés, el objeto del libro son las clases dominadas (no conscientes de ser mexicanas, que no modelan el país a su imagen), pero no se les concede el derecho de proponer sus propios conceptos como fundamentos. (Aguilar Mora 44)

Ahora bien, Aguilar Mora parece olvidar que está analizando una obra literaria, no una obra de Historia. El laberinto de la soledad fue escrito por un hombre de letras, no por un historiador. En este sentido, podemos decir que ha caído en una trampa discursiva. El ensayo puede tomarse libertades, asumir temas serios, frívolos o trascendentales; pero en sí, no dejará de ser un ensayo. Es decir: una aproximación a un tema sin agotarlo. Paz se ha tomado la libertad de intentar reescribir la Historia a partir de una concepción estética del pasado; su intención no era entonces hacer un tratado sociológico y científico, sino realizar esa filosofía que según Aristóteles estaba destinada a la poesía y no a la Historia. En este sentido, podemos decir que el ensayista critica el discurso histórico con una gran ventaja, ya que lo hace sin ser vulnerable, ya que al ser atacado podría decir: "pero esto es literatura, no Historia”. Al mismo tiempo, Aguilar Mora critica la obra de Paz al decir que en ella, "no se resuelve el problema del mexicano en ninguno de los términos propuestos a lo largo de todo el libro” (51). De la misma manera, podemos decir que Paz no se proponía resolver nada, sino mostrar una deficiencia de la metodología histórica; además ya he comentado que su interés no es hacer una continuación o mera superación de la obra de Samuel Ramos; el ensayista mexicano busca precisamente una universalidad a partir de los casos particulares que investiga.

Ahora bien, la visión que Paz presenta sobre el mito puede ser aplicada a cualquier cultura, pero él se centra básicamente en los mitos mexicanos y en particular en los que 
provienen desde el período precolombino. Esto es, el mito y la Historia pasan a formar los componentes necesarios para producir y comprender el hecho histórico en toda su complejidad. Aquí el mito no es visto como una fantasmagoría cultural o discursiva; por el contrario: el mito le inyecta verdad y razón a la Historia. Si la Historia es lo registrable, el mito es pues una especie de Historia invisible pero que le da fuerza a aquélla. Los mitos no se encuentran separados de la Historia, ellos contribuyen a determinarla y esta es la clave del libro: para salir del "laberinto de la soledad" uno debe enfrentar los mitos. Leemos entonces: "se ignora el lugar de la tumba de Cuauhtémoc. El misterio del paradero de sus restos es una de nuestras obsesiones. Encontrarlo significa nada menos que volver a nuestro origen, reanudar nuestra filiación, romper la soledad. Resucitar” (El laberinto 222). Por otro lado, Paz lleva a cabo una desconstrucción del tiempo; el tiempo ya no considerado como Historia, sino como una experiencia humana; como sensación. Desde este punto de vista, podemos observar la importancia del existencialismo, así como la empresa de todo el libro. Esto es, la relevancia de la noción de soledad debe ser interpretada como la premisa filosófica de El laberinto de la soledad. Asimismo, la interpretación de la verdadera Historia de México debe tener como su punto de partida el desciframiento de los mitos: "La extraña permanencia de Cortés y de la Malinche en la imaginación y en la sensibilidad de los mexicanos actuales revela que son algo más que figuras históricas: son símbolos de un conflicto secreto, que aun no hemos resuelto. Al repudiar la Malinche ... el mexicano rompe sus ligas con el pasado, reniega de su origen y se adentra sólo en la vida histórica” (El laberinto 225).

De la misma manera, para el filósofo mexicano Leopoldo Zea, los latinoamericanos ven el pasado como algo que hay que eliminar y el futuro como una abstracción más allá de su propia realidad. Pero para el filósofo, el pasado no es algo que se elimine; el pasado, si no es plenamente asimilado, se hace siempre presente (Zea, Dos etapas 23). Así, la asimilación es vista como una necesidad perentoria que hay que satisfacer a partir de la toma de conciencia del proceso en cuestión, al ser esto alcanzado, será entonces posible lograr la “emancipación mental” (Zea, La filosofía americana 25). En consecuencia, el pasado debe asumirse como propio, sin tratar de escapar de él, puesto que es él quien determina al presente y quien da forma a la identidad cultural. El pasado no puede "amputarse”, ya que es parte intrínseca de la realidad social del individuo; se puede ignorar, pero no se puede corregir; se puede olvidar, pero no se puede transformar. En cambio, sí se puede corregir el presente: conociendo y asumiendo el pasado. Un pasado que no está sólo vinculado a la realidad americana sino a la realidad total del hombre. Más aún: es necesario reconocer la fuerza del pasado para así realizar en el futuro la unión de todas las historias en una Historia Universal. Esto es, el futuro se convierte en el elemento determinante de la Historia; determinante porque es considerado desde una perspectiva positiva; no bárbara. El futuro es, en fin, la proyección mejorada del presente. Sin el futuro, la Historia se concebiría como un estatismo inoperante e innecesario. En este sentido, Paz cree que la soledad no es meramente un problema del mexicano, pero de la humanidad en su totalidad. Dice así:

La soledad, el sentirse y el saberse solo, desprendido del mundo y ajeno a sí mismo, separado de sí, no es característica exclusiva del mexicano. Todos los hombres, en algún momento de su vida, se sienten solos; y más: todos los hombres están solos. Vivir, es 
separarnos del que fuimos para internarnos en el que vamos a ser, futuro extraño siempre. La soledad es el fondo último de la condición humana. El hombre es el único ser que se siente solo y el único que es búsqueda de otro. Su naturaleza ... consiste en un aspirar a realizarse en otro. El hombre es nostalgia y búsqueda de comunión. Por eso cada vez que se siente a sí mismo se siente como carencia de otro, como soledad. (El laberinto 341)

Pero, la reconciliación siempre es posible: "la plenitud, la reunión, que es reposo y dicha, concordancia con el mundo, nos esperan al fin del laberinto de la soledad" (El laberinto 342). Ya que cada mito, según el ensayista, consiste en la necesidad de encontrar el centro del mundo del cual hemos sido expulsados. Encontrar ese centro es detener el tiempo cronométrico y comenzar el tiempo mítico; que es precisamente hacernos reflexionar sobre una nueva manera de concebir la Historia, y de escribirla.

Por otro lado, la visión de la Historia que nos presenta el poeta mexicano en El laberinto de la soledad tiene implicaciones directas con su noción del tiempo. Para Paz, hay un tiempo histórico arbitrariamente construido donde existe una sucesión abstracta y cronométrica; también existe un tiempo mítico, no cronométrico, que se concibe como un presente continuo. Por eso:

La medición espacial del tiempo separa al hombre de la realidad, que es un continuo presente, y hace fantasmas a todas las presencias en que la realidad se manifiesta, enseña Bergson.

Si se reflexiona sobre el carácter de estas dos opuestas nociones, se advierte que el tiempo cronométrico es una sucesión homogénea y vacía de toda particularidad. Igual a sí mismo siempre, desdeñoso del placer o del dolor, sólo transcurre. El tiempo mítico, al contrario, no es una sucesión homogénea de cantidades iguales, sino que se halla impregnado de todas las particularidades de nuestra vida: es largo como una eternidad o breve como un soplo, nefasto o propicio, fecundo o estéril.

Esta noción admite la existencia de una pluralidad de tiempos. Tiempo y vida se funden y forman un solo bloque, una unidad imposible de escindir. Para los aztecas, el tiempo estaba ligado al espacio y cada día a uno de los puntos cardinales. Otro tanto puede decirse de cualquier calendario religioso ... Sin duda la concepción del tiempo como presente fijo y actualidad pura, es más antigua que la del tiempo cronométrico, que no es una aprehensión inmediata del fluir de la realidad, sino una racionalización del transcurrir. (El laberinto 357-59)

En cuanto a las dimensiones del tiempo, pasado y presente son términos que se unen como vasos comunicantes. Paz interpreta el presente no sólo como una continuación del pasado sino como una aparición de aquél sobre éste. Él no quiere construir un sistema sobre la Historia, más bien se esfuerza en mostrar que los sistemas interpretativos sobre la Historia son obsoletos, y propone que nos detengamos ante ella para interpretarla y para entenderla:

El defecto de [las] interpretaciones [deterministas] como la que acabo de bosquejar reside, precisamente, en su simplicidad. Nuestra actitud ante la vida no está condicionada por los hechos históricos, al menos de la manera rigurosa con que el mundo de la mecánica, la velocidad o la trayectoria de un proyectil se encuentra determinada por un conjunto de factores conocidos. Nuestra actitud vital — que es un factor que nunca acabaremos de conocer totalmente, pues cambio e indeterminación son las únicas constantes de su ser- 
también es historia. Quiero decir, los hechos históricos no son nada más hechos, sino que están teñidos de humanidad, esto es, de problematicidad. Tampoco son el mero resultado de otros hechos, que los causan, sino de una voluntad singular, capaz de regir dentro de ciertos límites su fatalidad. La historia no es un mecanismo y las influencias entre los diversos componentes de un hecho histórico son recíprocas, como tantas veces se ha dicho. Lo que distingue a un hecho histórico de los otros hechos es su carácter histórico. O sea, que es por sí mismo y en sí mismo una unidad irreductible a otras. Irreductible e inseparable. Un hecho histórico no es la suma de los llamados factores de la historia, sino una realidad indisoluble. Las circunstancias históricas explican nuestro carácter en la medida que nuestro carácter también las explica a ellas. Ambas son lo mismo. Por eso toda explicación puramente histórica es insuficiente — lo que no equivale a decir que sea falsa. (El laberinto 209)

Como observamos en esta cita, Paz rechaza las posturas adeptas al determinismo histórico. No es posible así — según su interpretación— predecir el desenvolvimiento de la Historia, ni siquiera pensar en la continuidad rectilínea de los acontecimientos; los hechos determinan al individuo, en la medida en que el individuo determina los hechos. La historicidad del individuo radica no sólo en su pasado y en su capacidad de hacer Historia, sino en la toma de conciencia de su individualidad. De este modo, el pasado no se ha ido, sino que se encuentra presente de manera inmanente en la vida cotidiana de la sociedad. El pasado y el presente, se encuentran de alguna manera más allá de la tangibilidad histórica; esto es, se hallan dentro del espíritu del pueblo. Una permanencia de este tipo muestra una actitud crítica e innovadora ante la historiografía, porque el ensayista no se conforma con decir que la Historia es pasado, y que determina el presente, sino que esa permanencia es como un secreto, como algo oculto que hay que revelar. O lo que es lo mismo, la Historia tiene varias dimensiones como las habitaciones del laberinto. El laberinto de la soledad se convierte entonces en la soledad del laberinto. El individuo no está sometido a la Historia, sino que a pesar de ser parte de ella, puede también determinarla. Así pues, la conciencia y el pensamiento del individuo determinan su existencia, y de alguna manera, se evoca el cogito ergo sum cartesiano: pensar es existencia.

El pensamiento y la existencia no se conciben como entidades separadas, sino como elementos heterogéneos dentro de una permanente unidad individual. En varios de sus ensayos posteriores y especialmente en Tiempo nublado (1990), el autor hace énfasis sobre la importancia de la individualidad en el contexto de su historicidad. En este libro, Paz analiza no sólo la voluntad del individuo, sino la voluntad social; en efecto, en la voluntad un país afirma su individualidad; como es el caso de Polonia descrito en el ensayo "Crónica de la libertad” de este mismo libro. Por otro lado, el análisis que lleva a cabo Paz puede ser aplicado al hombre contemporáneo, porque es precisamente en la particularidad donde se devela lo universal. En este sentido:

la complejidad de la sociedad contemporánea y la especialización que requiere el trabajo extienden la condición abstracta del obrero a otros grupos sociales. Vivimos en un mundo de técnicos, se dice. A pesar de las diferencias de salarios y de nivel de vida, la situación de estos técnicos no difiere esencialmente de la de los obreros: también son asalariados y tampoco tienen conciencia de la obra que realizan. El gobierno de los técnicos, ideal de la sociedad contemporánea, sería así el gobierno de los instrumentos. (El laberinto 20562) 
Es esto, pues, un reproche a la sociedad contemporánea y a las interpretaciones históricas que no ven a la crítica como un medio para corregir el destino humano. Pero dentro de las diversas formas de ver la Historia, la complejidad de capas que Paz encuentra en ellas es quizá una de los elementos más importantes de su postura: “En nuestro territorio conviven no sólo distintas razas y lenguas, sino varios niveles históricos” (El laberinto 146) Aquí podemos apreciar los grandes lineamientos de su concepcion de la Historia: la Historia como movimiento, como contraposición, como pasado inserto y manifiesto en el presente, como modernidad (lo heterogéneo dentro de la unidad), como confluencia de varias etapas históricas, como desplazamiento de pueblos, como cambio y transformación y como presente. Es decir, la Historia tiene para el ensayista mexicano una manifestación múltiple, compleja y heterogénea. Esta última cita, que aparece en el quinto párrafo de El Laberinto, es crucial porque sirve de marco teórico para el resto del libro: es una especie de anticipación y de preámbulo, ya que, descifrar el enigma del pachuco, ${ }^{5}$ ¿no es acaso descifrar esa Historia nutrida de modernidad, de contradicción y de vitalidad histórica? Paz interpreta la Historia no a partir de lo general sino a partir de lo particular. Esta opinión es similar a la Santí:

A primera vista estamos ante una estructura de razonamiento inductivo: va de lo particular a lo general. De "ciertos mitos" a la "historia de México", y de ahí finalmente a la derivación de un "ritmo vital e histórico" [...] ese razonamiento inductivo es sólo parte de un proceso hermenéutico más complejo, pero por lo pronto notaremos que es esa la estrategia general del libro: inferir una historia, y sucesivamente un ritmo que la explique, a partir del análisis de una serie de "mitos”. En este sentido, el libro procede empíricamente, a partir de lo más inmediato, para entonces razonar fenomenológicamente, en el sentido estricto que tiene el término "fenomenología”: una teoría de las apariencias. ("Introducción” 76)

Entonces, el ensayista trata de definir no sólo al mexicano (y su mexicanidad) sino también su concreción social, su historicidad; por eso dice de los pachucos: "queramos o no, estos seres son mexicanos, uno de los extremos a que puede llegar el mexicano" (Laberinto 149). Es decir, el mexicano no se ha escapado de la Historia: es Historia. En este sentido, la soledad de El laberinto es básicamente la soledad que el Hombre siente ante la Historia, perfilada por el asombro de ser y de existir.

En El laberinto de la soledad hay una visión de la Historia implícita, que atañe y concierne al individuo (al pachuco por ejemplo); y otra explícita, que concierne a todo el ser humano. La soledad del individuo puede sentirse en ambos renglones; la soledad del pachuco es también doble: ante sí y ante el mundo, pero no puede escaparse de la Historia inmediata que le circunda. Los Estados Unidos son así una especie de receptáculo que comprende la Historia individual de ese grupo, pero es también parte de un estadio más

\footnotetext{
${ }^{5}$ El pachuco, que es lo que hoy podríamos llamar “chicano”; es decir, los hijos de los inmigrantes mexicanos nacidos en los Estados Unidos, Paz los define así: "los 'pachucos son bandas de jóvenes, generalmente de origen mexicano, que viven en las ciudades del Sur y que se singularizan tanto por su vestimenta como por su conducta y su lenguaje. Rebeldes instintivos, contra ellos se ha cebado más de una vez el racismo norteamericano . . . El 'pachuco' no quiere volver a su origen mexicano; tampoco — al menos en apariencia — desea fundirse a la vida norteamericana. Todo en él es impulso que se niega a sí mismo, nudo de contradicciones, enigma” (El laberinto 148).
} 
grande que es la Historia mundial. Al interrogarse y dar respuestas acerca del pachuco, Paz particulariza la situación histórica de los individuos del sur de California y muestra al mundo su dramática situación de identidad cultural y pone de relieve uno de los temas que más lo apasiona: la modernidad. Los pachucos son en sí un producto de la modernidad; ellos encarnan todos sus signos: dualidad cultural, heterogeneidad, contradicción y marginación étnica, marginación económica, relación entre el débil y el poderoso, como dirá luego en su libro Tiempo nublado: “en cuanto a nuestra relación con los Estados Unidos: sigue siendo la vieja relación entre el fuerte y el débil, oscilante entre la indiferencia y el abuso, la mentira y el cinismo. La mayoría de los mexicanos tenemos la justificada convicción de que el trato que recibe nuestro país es injusto” (155). El laberinto puede verse también como una crítica a los historiadores que hablan del individuo y lo reducen al sustantivo "Hombre". Aquí Paz pone de relieve la universalidad de la persona, pero también su individualidad. De esa manera, el movimiento de la Historia no es visto, desde esta perspectiva, como un movimiento lineal y homogéneo, sino confuso, contradictorio, ramificado: como el laberinto. Al tratar de definir —al menos en sus rasgos más generales o típicos — la personalidad del mexicano, Paz advierte que la mexicanidad es algo exclusivo de ese país y que no puede encontrarse en ningún otro. Esto lleva como consecuencia que cada país y región son únicos, aunque dentro del grupo de países hispanoamericanos compartan un pasado común. El ensayista pone fin a la idea de que el hispanoamericano es idéntico en todas partes, y observa que éste posee características individuales específicas que hay que tomar en cuenta y que no se pueden pasar por alto al intentar elaborar un concepto universal que los identifique. Así, lo que se presenta en los subtítulos del ensayo como particularidades concretas ("pachuco", "hijos”, "máscaras”, etcétera) son en realidad lecturas del individuo ante la Historia y de la concreción del Hombre ante su presente; Paz es el ensayista de la particularidad y lo particular contiene para él lo universal.

El laberinto de la soledad es un libro sobre la relación del Hombre con su circunstancia histórica, pero para hacer este análisis, Paz ha tenido que recurrir al pasado, que se encuentra — en varios sentidos - operando en el presente, y antes de ser una directa proyección del pasado, el presente está asociado también a una serie de valores mítico-poéticos; así: la Historia, es vista al trasluz del mito. Estas creencias pasadas están particularmente concebidas por el ensayista mexicano como las creencias aztecas que se encuentran de manera latente en el inconsciente colectivo de los mexicanos. En Posdata, al explicar la arremetida de 1968 de Tlatelolco, en donde el ejército mexicano mató a centenas de estudiantes, dice: "La matanza de Tlatelolco nos revela que un pasado que creíamos enterrado está vivo e irrumpe entre nosotros. Cada vez que aparece en público, se presenta enmascarado y armado; no sabemos quién es, excepto que es destrucción y venganza. Es un pasado que no hemos sabido o no hemos podido reconocer, nombrar, desenmascarar" (40). Se trata entonces de "algo que no pasa, algo que pasa sin pasar del todo, perpetuo presente en rotación” (Posdata 111). Paz se ha volcado al pasado azteca también para destacar que hay una Historia visible y otra invisible. "Del mismo modo", dice, "que la Roma cristiana prolongaba, rectificándola, a la Roma pagana, la nueva ciudad de México era la continuación, la rectificación y, finalmente, la afirmación de la metrópoli azteca” (Posdata 124-25). Más aún: 


\begin{abstract}
hay otro México. No me refiero de ninguna manera a una entelequia ahistórica y atemporal; tampoco a un arquetipo en el sentido de Jung o de Mircea Eliade. Es posible que la expresión “el otro México” carezca de precisión, pero la verdad es que no he encontrado ninguna otra más a propósito. Con ella pretendo designar a esa realidad gaseosa que forman las creencias, fragmentos de creencias, imágenes y conceptos que la historia deposita en el subsuelo de la psiquis social, esa cueva o sótano en continua somnolencia y, asimismo, en perpetua fragmentación. Es una noción que viene tanto del subconsciente (individual) de Freud como de la ideología (social) de Marx. Una ideología que representa lo que el mismo Marx llamaba "la conciencia absurda del mundo" y que nunca es consciente del todo. Sin embargo, las concepciones de Marx y Freud, cada una por razones diferentes y que no analizaré aquí, me parece que no explican la totalidad del fenómeno: la existencia en cada civilización de ciertos complejos, presuposiciones y estructuras mentales generalmente inconscientes y que resisten con terquedad a la erosión de la historia y a sus cambios. (Posdata 109-10)
\end{abstract}

La Historia visible es aquélla inmediata, perceptible por todos los individuos en su cotidianidad; invisible, por el contrario, es la que se encuentra en lo más profundo de sus creencias. El pasado reaparece porque “es un presente oculto” (Posdata 111), y en la medida en que se pueda develar ese pasado, se podrá reconocer las verdaderas características del presente. Por eso dice en Posdata, que: "la crítica de México y de su historia [...] debe iniciarse por un examen de lo que significó y significa todavía la visión azteca del mundo ... La crítica de México comienza por la crítica de la pirámide” (135). El pasado, aparente forma oculta, además de ser tiempo, es también creencia hecha presente; Paz añora también ese origen, donde lo primigenio era un continuo presente. Vemos entonces que Paz propone en primer lugar una toma de conciencia del desprendimiento del origen; y, por otro lado, espera que este "centro del mundo" sea buscado, inclusive, a través del "laberinto". Reconciliarse con ese tiempo perdido, ausente en el individuo moderno, es la superación de la "soledad”, la cesación de la Historia (El laberinto 360).

\title{
BiBliografíA
}

Aguilar Mora, Jorge. La divina pareja: Historia y mito. Valoración e interpretación de la obra ensayística de Octavio Paz. México: Ediciones Era, 1978.

Castro-Gómez, Santiago. Crítica de la razón latinoamericana. Barcelona: Puvil Libros, 1996.

Eliade, Mircea. Myth and Reality. William R. Trask, trad. Nueva York: Harper \& Row, 1968.

García-Pelayo y Gross, Ramón. Pequeño Larousse Ilustrado. Barcelona: Ediciones Larousse, 1992.

Hegel, G.W.F. Fenomenología del espíritu. Wenceslao Roces, trad. México: Fondo de Cultura Económica, 1981.

Homick, Stephen J. "Soledad y comunión: Octavio Paz y el desarrollo de la idea mexicana de laHistoria”. Cuadernos americanos 128 (1980): 99-113.

Mermall, Thomas. “Octavio Paz: El laberinto de la soledad y el sicoanálisis de la Historia”. Cuadernos americanos 156 (1968): 97-114. 
Oviedo, Rocío. “El tiempo de la historia en Octavio Paz”. Insula 46 (1991): 24-26.

Paz, Octavio. El laberinto de la soledad. Enrico Mario Santí, ed. Madrid: Cátedra, 1995. El ogro filantrópico: Historia y política. 1971-1978. México: Joaquín Mortiz, 1979. Posdata. México: Siglo xxi Editores, 1970.

Tiempo nublado. Barcelona: Editorial Seix Barral, 1990.

Santí, Enrico Mario. “Introducción”. El laberinto de la soledad de Octavio Paz. Madrid: Cátedra, 1995. 13-137.

Villegas, Abelardo. La filosofía de lo mexicano. México: Fondo de Cultura Económica, 1960.

Zea, Leopoldo. Dos etapas del pensamiento en Hispanoamérica: Del romanticismo al positivismo. México: El Colegio de México, 1949.

La filosofía americana como filosofía sin más. México: Siglo xxi Editores, 1969. 